AC 2012-4000: ENGINEERING AND TECHNOLOGY EDUCATION IN BANGLADESH: COMPARATIVE STUDY OF THE PUBLIC AND PRIVATE UNIVERSITIES FOR PROBLEMS AND PROSPECTS.

Dr. Rafiqul Islam, Northwestern State University 


\title{
Engineering and Technology Education in Bangladesh: Comparative Study of the Public and Private Universities for Problems and Prospects.
}

\begin{abstract}
Bangladeshi engineering and technology education has been experiencing radical transformation and development over the last twenty years. This field which was monopolized by a number of public institutions for a long time is being shared by a growing number of private universities and colleges. The higher education institutions are the largest stakeholders to adapt the technological advancement for betterment and efficient rendering of education to the learning community. Their goal is to play a vital role in promoting productivity, innovation, entrepreneurship, gender mainstreaming, and overall socio-cultural advancement. The key to achieving high rates of economic growth (around 7 percent) and to distribute equitably to her population lies in development and utilization of her abundance human resources. The higher education is highly subsidized in the public institutions whereas it is partly in the private institutes. There is growing interest in the current status of engineering and technology education in Bangladesh due to the globalization of engineering profession. This study concludes with the comparison of public and private institutions in terms of curriculum, admission policies, .availability of information and communication technology (ICT) facilities, cost etc. The collaboration and influence of the American universities will also be discussed.
\end{abstract}

The employers in Bangladesh are demanding engineers and technologists to be good team players with excellent communication skills to compete locally and globally. In recent years almost sixty percent of the continuously increasing work visas allocated by our Government are filled up by the engineers and technologists from Southeast Asian countries. A study of the reasons and means of enthusiasm and interest in engineering and technology programs there will be presented. Recently our government is getting pressure from industries, businesses and politicians to even increase the work visas for foreign born engineers as there is an acute shortage of qualified engineers here. The women whom represent nearly fifty percent of the population are also being motivated to enroll and finish the program by understanding that the careers in these areas are exciting, rewarding and accessible. The author will find some common ground to motivate the students toward engineering and technology programs in the United States.

Introduction

Around this time Bangladesh has celebrated 60 years of engineering and technology education. It was dominated by BUET (Bangladesh University of Engineering and Technology) and four other public engineering universities offering engineering courses. The language of delivery is English. Engineering education has been booming throughout all these years. As a result of Gov. Policy, public prestige remuneration, high market demands and diversity, the high school graduates enthusically compete with one another to enroll to limited numbers of spots. This is a recognition of influence of engineering education in the society of Bangladesh. 
For more than last ten years the US Government had no choice but to keep on increasing working visas for importing engineers and technologists from overseas to coop with the severe shortage. About sixty percent of the work visas $(\mathrm{H}-1 \mathrm{~B})$ are filled up by the engineers and technologists from Southeast Asian countries. The author looked at those countries for reasons of motivation towards engineering and technology professions. This is recognition of influence of engineering education in the society of that part of world. The prestige in the society as well as the engineering friendly high school curriculum provide the means to create this kind of enthusiasm and interest for this remarkable specialties. Here in the US the engineering and technology profession is perceived as isolating and lacking in social relevance. Engineering is not featured in popular television program and usually gets overshadowed in news reporting even though technology dominates the social landscape. Good news is that the politicians and the business community are demanding the cancellation of $\mathrm{H}-1 \mathrm{~B}$ visa caps to attract more qualified engineers to fill up the vacant positions.

The public universities were playing significant roles in providing skilled human resources until the private universities were permitted to be set up in 1992 under the private university Act. Now there are more private universities compared to public universities and undergraduate engineering education is highly dominated by them. The Act requires that at least 5 percent of the student body receives full tuition waivers. This is intended to help poor students take advantage of these institutions. Since then the enrollment in private universities has accelerated even though the gross enrollment ratio is not high enough. It is believed that students from rich families who attend private universities create vacancies in public universities for other students ${ }^{1}$.

The pace of industrialization in Bangladesh has increased and noticeably diversifies from the seventies. The engineering and technology education system has produced a good number of well skilled engineers who develop the industrial sectors and infrastructures. The globalization of engineering education and professionals brought new challenges to the future of engineering. To cope with it, the engineers must have effective communication skills to function properly in a multidisciplinary working environment and must understand their potential and ethical responsibilities to compete locally as well as globally ${ }^{2}$. Still there in lack of linkage to employers and the job market. The author will focus in that area.

The private institution represents the fastest growing section in higher education. The growth and expansion of this section shows the willingness of parents to pay for the education of their children on one hand and their success in responding to the aspiration of the people on the other hand. The Private sector of engineering education is self-financing and at times produces a profit. The main source of income is student fees. The students are interested as many of them offer market-oriented courses that almost guarantee them a job upon graduation. They save on salaries of the faculty by employing teaching staff on a part-time basis or by relying on teachers from already established public universities. The private universities are very often linked with universities abroad. This connection helps the students to move to USA, Canada, UK, Australia, Germany, Japan etc. for higher studies. Even though all the private universities started functioning in hired premises for classrooms, laboratories and offices, they started building campuses using the interest from the certificates of deposits (CD) of the profits ${ }^{3}$. 


\section{Admissions}

Access to university education specially engineering and technology education is rather limited in Bangladesh due to limited number of seats in public universities as well as high tuition fees charged by the private universities.

Undergraduate admission test is one of the most intensive, written examinations in Bangladesh as it only offers limited number of seats in each academic year. BUET is the oldest Engineering institute in the region and is regarded as the best university for technical education. The admission test is one of the most intensive written examinations in Bangladesh. Students with an A+ percentage in Mathematics, Physics, Chemistry, and English of their higher secondary certificate (after twelve years) examination are allowed to take the admission test. The screening process permits 8000 students to sit for the admission test from a pool of approximately 40000 applicants. Only about 1000 students are allowed to get admission after the admission test. There is no requirement for verbal interview for the undergraduate applicants.

There are 26 seats for the foreign students in undergraduate level. The pre-requisite qualification for admission is HSC (Higher Secondary Certificate) or GCE A level or equivalent with good grades in mathematics, physics, and chemistry ${ }^{4}$.

North-South University (NSU) was the country's first government-approved private institution of higher education established in 1992. The university where the language of introduction is English offers 26 undergraduate degree programs including electrical and telecommunication engineering and electrical and electronic engineering. It is one of the top ten private universities in Bangladesh ${ }^{5}$. All of them follow very similar admission policies. As an example, the admission eligibility of East-West University (EWU) is reported here.

1. Minimum GPA of 2.50 in both SSC (Secondary School Certificate, after 10 years) and HSC Examinations. Or, At least one first division either in SSC or in HSC. No third division is allowed. (Students must have Mathematics and Physics in HSC or A level) or

2. GCE "O" Level in 5 subjects and "A" Level in 2 subjects with at least 4 B's and 3 C's; or

3. American High School Diploma, and

4. Acceptable EWU Admission Test Score

5. Final selection for admission will be based on the total scores obtained out of 100 weightage as follows:(a) Admission Test Score(50\%), (b) Results of SSC/'O' level (20\%)and (c) Results of HSC/'A' level/Equivalent exams(30\%)

For admission test waiver the candidates seeking admission in the Faculty of Sciences and Engineering must have minimum CGPA 3.5 in Math and Physics separately in HSC/A level examinations in addition to a minimum total score of 1500 in SAT (considering Critical Reading, Math and Writing). Admission test will also be waived for the GPA 5.00 without 4th subject marks in the latest SSC \& HSC exams or 7'As' in 'O' level (at one sitting) and 3 'As' in 'A' level. Students who have completed a two-year Bachelor's degree from a recognized university can apply for admission into the four-year undergraduate program. However, EWU will consider 
applications for credit transfer only in cases where previous academic performance meets EWU degree requirements.

Foreign Students particularly who come from other systems like US High School Diploma, Indian/Nepalese system etc. (not from SSC/HSC or O/A Level etc. system) the admission eligibility will be as follows:

- Must be 12 years of schooling.

- SAT score of 1100 or

- Pass with at least upper 50\% marks/grade of their own education system.

- Foreign students fulfilling the admission eligibility need not appear at the Admission Test.

An equivalence committee will assess and recommend for satisfactory grade for the applicants who seek admission in EWU with US High School Diploma or who come from other systems. A committee will assess and recommend for waiver of Admission Test, Scholarship etc. (if applicable) for foreign students and the students from other systems ${ }^{6}$.

Curriculum

At the beginning, the academic programs of BUET followed the British undergraduate curriculum. Engineering curriculum went through significant changed during 1953 when a linkage program was developed with Texas Agriculture and Mechanical College (Now Texas A\&M University) of USA. Since then, the institute has maintained its relationship with foreign universities through different linkage programs to develop Staff, course-curricula, laboratories and library facilities. From 1974 the institute adopted the semester systems as in US universities and colleges and the course curriculum was based on American systems. As a developing country the engineering curriculum in Bangladesh needs to go through continuous modernizations. Even thorough different development phrases of the evolving engineering curriculum took place in course of time, no attempt has been made to determine with any precision where the engineering curriculum stands today.

In engineering education systems, real life problems based learning must be adopted as it is an effective way of solving open-ended engineering problems. Interaction with industry personal and trips to the real engineering sites not only strengthen the learning abilities, but also gives the students ideas about their future job properties and responsibilities. The author suggests the formation of an industry advisory board which will definitely be helpful in developing the course curriculum geared towards industry needs. Lecture based elements with hand-on laboratories seldom talk about how practicing engineers operate, the problems they face and the way they solve the problems. This connection will motivate the students toward fulfillment of their goals. Moreover, the student will develop different skills because of the multidimensional competition among themselves ${ }^{2}$. Consequently, multinational companies are hiring engineers in their projects which are globally distributed. So, an engineer has to be equipped to compete with engineering graduates from different universities of the world.

The IUB (International University of Bangladesh) is committed to producing graduates of international standard who will be equipped to provide new leadership to the national economy through skilled employment, entrepreunuriship and/or applied research. The curriculum of IUB has been carefully designed to provide students with communication skills, socio-cultural 
background, applied skills or project based experience and an area of sub specialization. During the first year, the students take courses on learning skills, national culture and electives in arts and science.

In order to ensure international standards in teaching and to provide wide option for students to study abroad or acquire international experience, IUB maintains peer relations with a large number of universities and institutions abroad. The program of study and academic regulation of this university are based on the American course structure and semester system.

Islamic University of Technology (IUT) is an internationally recognized educational and research institution in Bangladesh. It is regarded as one of the top universities for technical education in Bangladesh. The main objective of IUT is to contribute in developing the human resources of the member states of the Organization of Islamic Countries, particularly in different fields of engineering and technology. IUT receives direct endowment from OIC member countries and offers scholarships to its students in the form of free tuition, boarding, lodging and medicare. In a financially constrained country like Bangladesh this type of institution is a plus towards its development.

In BUET the curriculum is designed in such a way that there will be no classes or laboratory works for the last two weeks of the semester before the final examinations. During this period called preparatory leave, the students can study hard to do well in the finals. Group studies around day and night bring a learning environment in the dorms and libraries. They help each other to get a better understanding of the course materials. The students like it as it gives them some valuable extra time to add their acts together. There is no proof that two weeks make them better engineers but the graduates of that institute are doing very well locally and globally. To the contrary, here in the United States the final examinations start the next day of the final day of classes. Most of the students do not get enough time to review all the materials of several courses to do well in the finals. As a result the decrement of grade from the mid-term is common and it may result in not passing a course. The author suggests the implementation of it in our curriculum to see the effect.

Information and Communicating Technology (ICT)

In engineering and technology education there is a need for the creation of technology based higher education (TBHE) environment in higher education institutes (HETs). The necessary logistic like multimedia, projectors, computers, internet connectivity with necessary bandwidth, skilled e-content development group, technology-friendly HEI administration, adaptively of the learners to TBHE environment do not persist at a point at a satisfactory level in Bangladesh.

The TBHE environment for dissemination of information in limited form is available in most of the public universities in Bangladesh. However, a few private universities are promoting TBHEfor authentic delivery of learning contents in electronic form through web and other media. The higher education institutions are using ICT in learning and teaching process to increase the quality, efficiency, and disseminating of education. 
The public as well as private universities design useful websites for disseminating general information to the visitor as their major technology oriented activity with the exception of a few HEIs which provide more technology oriented services to the students. The TBHE support provided to their students is authentic access to course materials within and outside the campus, online admission of assignments and term papers, access to online transcripts to the students and respective advisors, using log to monitor online activities of students, online discussion forum, providing digital library, etc ${ }^{\mathrm{T}}$.

There is a huge competition among most of the top universities to produce graduate of international standard to deal with the overwhelming local and global challenges. Almost all the universities have ICT facilities to keep the universities in the race of engineering education and scholarly communications private. Universities are now making praiseworthy contribution in the development of ICT. It is found out from several reports that some of the leading private universities have more ICT facilities than some public universities ${ }^{8}$.

The overall literary state stands at 56 percent in Bangladesh. Government had realized to develop strategies for technology based cost-effective literacy program as the conventional system of education was not adequate to meet the demand. There was a compelling need for exploring and introducing new modes of education and training. This led to the creation of Bangladesh Open University for open and distance learning (ODL) by the act of the parliament of the People's Republic of Bangladesh. The increased availability of ICT's have the potential to solve a number of problems and issues associated with the provision of distance education courses ${ }^{9}$. The engineering and technology universities must produce well informed graduates in these fields to fulfill their commitment to the nation.

\section{Cost}

The private universities act of 1992 requires that private universities should offer scholarships to five percent of its poor but meritorious students. The public universities are almost entirely financed by the government even though they charge nominal tuition fees. Most of the students get some sort of scholarships or financial help from different organizations which can take care of their room and board expenses. The students can borrow textbooks, or pay a nominal fee to rent them. In comparison to American expenses, it is quite low.

For the top level private university the tuition and fees for undergraduate engineering program is $\$ 1800.00$ per year. This is enormously high for the average Bangladeshi parents who mainly bear the expences ${ }^{10}$.

\section{Conclusion}

The optimal utilization of dense and growing population is to sustain an economic growth of more than seven percent. So, the importance of education especially engineering and technology education is to be emphasized. This paper has pointed out the increase of opportunities for access to the engineering education because of increasing number of private universities. Unfortunately, only a few percent of those 18 to 23 years old get access to the engineering and technology education. This can be increased mostly by the private universities as the public universities 
cannot cope with the increasing financial burden. It is also mentioned that the public as well as private universities have strong similarities to those in the engineering and technology universities in the United States in their curricula, books, and faculty training. Also, there is similarity between the politicians who always talk big about engineering education but fail to increase the funding to make it happen. Interaction with Southeast Asian countries including Bangladesh in engineering and technology fields will bring tremendous benefit to our nation even though it is not a permanent solution to our overall shortage of technical labor force.

As the access to the private universities for engineering and technology education is restricted to children from affluent families who can pay extremely high tuition fees, the author proposes an increase to at least $8 \%$ instead of $5 \%$ of the student body receive full tuition waver. Private universities, no doubt have contributed to responding to the social demands for higher education by absorbing a good number of students who otherwise could not have received university degrees. However, the quality of the technical courses offered by private institutions is frequently questioned. Their main goal is to maximize profit. Some have taken advantage of the mushrooming demand for skill-oriented courses in the employment market and have become degree granting machines. This is why, the author feel the necessity of introducing quality control mechanisms in the private universities to ensure certain minimum inputs, processes, and outputs. The state has to form some sort of accreditation council other than the University Grans Commission of Bangladesh the statutory apex body responsible for maintaining standard and quality in higher education. No meaningful comparison is done by any agency or organization so far to establish which one is better. The private institutes should siege the opportunity and leverage of significant benefit by adapting themselves to TBHE environment.

The preparatory leave for at least one week before final examinations will definitely be beneficial to the students in the United States.

Bibliography

1. C.P.S Charrham "Higher Education", current status and future possibilities in Afghanistan, Bangladesh, Bhutan, India, Maldives, Nepal, Pakistan, and Sri Lanka. Published in Analytical Reports in International Education vol. 2 No. , March 2008, pp. 29-48.

2. K.B. Kabir, M.S. Khan I. Mahmud, 'Novel Ideas of Engineering Education in Bangladesh', published in Chemical Engineering Research Bulleting 12 (2008)-11-19 http://en.Wikipedia.org/wiki/Bangladesh_ University_of_Engineering _ and_Technology.

3. Mahmudul Alam, M. Shamsul haque etc., 'Private Higher Education in Bangladesh' Paper Presented at the Policy Forum on Private Higher Education in Africa Held on 2-3 November, 2004, in Accra, Ghana, 30p, e-publication.

4. http:en.wikipidia.org/wiki/Bangladesh_University_of_Engineering_and_Technology

5. http://en.Wikipedia.org/wiki/North_South_University.

6. www.ewubd.edu/ewv/showDocument.php?documentid $=123$

7. http://www.digitallarning.in/articles/article-details.asp?articleid=113\&typ=COUNTRY.

8. Md. Anwarul Islam \& Md. Saiful Alam 'Webometric Study of Private Universities in Bangladesh Malaysian Journal of Library's Information Sciences, Vol. 16, no. 2, August 2011, 115-116.

9. Md. Shafiqul Alam, ' Technology based Literacy Education Through Distance Mode in Bangladesh: Problems and Prospects, www.col.org?pcf2/papers/alam.pdf

10. www.ewubd.edu 


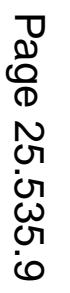

